\title{
28 Research Square \\ The air you breathe: Do nanoparticles pose a health risk?
}

\author{
Alison Buckley \\ James Warren \\ Alan Hodgson \\ Tim Marczylo \\ Konstantin Ignatyev \\ Chang Guo \\ Rachel Smith
}

\section{Video Abstract}

Keywords: Nanoparticles, Inhalation exposure, In vivo study, Rat, Tissue distribution, Lung clearance, Toxicity

Posted Date: February 25th, 2021

DOI: https://doi.org/10.21203/rs.3.rs-275891/v1

License: (c) (i) This work is licensed under a Creative Commons Attribution 4.0 International License.

Read Full License 


\section{Abstract}

Nanotechnology has long held the promise of a better tomorrow. But it's not without controversy. In a popular doomsday scenario, for example, we find our planet engulfed by self-replicating nano-bots, a runaway programming error in a nanomaterial designed to clean up the environment. True, the scenario is science fiction rather than science fact, but it does touch on the fear that nanomaterials pose a public health risk. Tiny nanoparticles can, in fact, nestle themselves in our bodies with a single breath. The question is, how long do they stay there? A UK study suggests that the long-term accumulation of nanoparticles in the vital organs of rats warrants a closer look at the bodily effects of nanomaterials. Most animal studies have shown that breathable nanoparticles that are lodged in the lungs are typically cleared within a few months, with fewer than 1 percent traveling to other organs, such as the brain, liver, or kidneys. But what happens to these particles long-term? To answer this, the UK researchers tracked iridium particles inhaled by rats for over 3 months. During the first week, their results seemed to agree with those reported in other studies; a small fraction of particles accumulated in the kidneys and liver. But in the liver, they appeared to pile up indefinitely. And, what's more, the particles were cleared much more slowly from the lungs than previously observed. Together, these findings suggest that continuous exposure to nanoparticles could present a long-term toxicity risk. But before regulators slap warning labels on products containing nanoparticles, researchers will have to address a few issues. First, they'll have to prove that the nanoparticle pathway observed in rats is the same in humans. They'll also need to extend their study to include much more common nanomaterials such as titanium dioxide and carbon black found in cosmetics and paints. While no imminent danger has been proven, least of all the threat of a ravenous gray goo, the researchers' findings are telling. At the very least, they provide grounds enough for doubling efforts to examine the effects of nanomaterials on the body. 